\title{
Glassy Carbon Electrode with Decorated Gold Nanoparticles for Horseradish Peroxidase/Polypyrrole Nanorod Biosensor
}

\author{
Yusran Daoa, Chanchana Thanachayanont, ${ }^{1}$ and Seeroong Prichanont ${ }^{*}$ \\ Department of Chemical Engineering, Faculty of Engineering, Chulalongkorn University, \\ Phayathai Road, Bangkok 10330, Thailand \\ ${ }^{1}$ National Metal and Materials Technology Center, Thailand Science Park, \\ Phaholyothin Road, Phatumthani 12120, Thailand
}

(Received February 10, 2015; accepted July 31, 2015)

Keywords: biosensors, immobilised enzyme, nanogold electrode, polypyrrole, electrodeposition, nano$\operatorname{rod}$

For the first time, a glassy carbon electrode (GCE) with decorated gold nanoparticles (nanogold electrode: NGE) was applied as an underlying substrate for template-free electropolymerisation of pyrrole (Py). The principal aim of this study was to investigate synergic effects of NGE and polypyrrole (PPy) on electrochemical responses. Effects of fabrication conditions (Py concentration and the number of scan cycles) on PPy film morphology and current responses were emphasised. Immobilisation of horseradish peroxidase (HRP) was concomitantly achieved with electropolymerisation of Py that completed a modified electrode for the amperometric detection of phenol, a model analyte. A NGE/HRP/polypyrrole (PPy) biosensor resulted in a 4.5-fold higher current response in comparison with that of a GCE/HRP/PPy. A synergy between AuNPs (of the NGE) and PPy was suggested. The initial Py concentration and a number of scan cycles for polymerisation were found to be the governing parameters for electrode surface morphology and electrochemical responses. Scanning electron micrographs revealed formation of homogeneous PPy nanorods under certain electropolymerisation conditions. Optimum conditions were determined at an initial Py concentration of $0.09 \mathrm{M}$ and 10 cycling numbers. NGE could certainly be applied as an underlying substrate for other enzyme/polymer or sole polymer matrices for detection of other analytes in biosensors and chemical sensors.

\section{Introduction}

Fabrication of enzyme biosensors generally concerns producing electrode platforms that are both electroactive and biocompatible for immobilised enzymes. Polypyrrole (PPy), a conducting polymer, is widely used for enzyme immobilisation due to its unique properties, namely good electrical conductivity, biocompatibility, stability under ambient conditions, and ease of fabrication. ${ }^{(1,2)}$ Incorporation of gold nanoparticles (AuNPs) into/on conducting polymer films has been popularly employed because of the large specific surface area, biocompatibility, and high conductivity of AuNPs. ${ }^{(3,4)}$ Therefore, the synergy between PPy and AuNPs leads to marked enhancements of electrochemical responses ${ }^{(5)}$ and detection sensitivities. ${ }^{(6)}$

${ }^{\bar{*}}$ Corresponding author: e-mail: seeroong.p@chula.ac.th 
One of the various methods for electrode modification with AuNPs is electrodeposition of nanoparticles on a planar electrode. Characteristics (size, particle density, and particle morphology) of the formed nanoclusters can be readily adjusted by controlling electrodeposition time and precursor concentration at a certain applied potential. ${ }^{(7)}$ The AuNP deposited electrodes (nanogold electrodes: NGEs) have been utilised as underlying substrates in various applications such as enzyme biosensors, ${ }^{(8)}$ DNA hybridisation biosensors, ${ }^{(9)}$ self-assembled monolayers (SAMs) on NGEs ${ }^{(9)}$ and on its own (without further modification) for electroanalysis of biomolecules. ${ }^{(10)}$ The published papers principally suggest that the high surface area of NGEs led to increases in immobilisation amounts of biomolecules of interest, thus boosting biosensor performances. Moreover, the film layers attached to nanogold surfaces, such as SAMs, ${ }^{\left({ }^{9}\right)}$ were found to possess different assembled structures from those on planar electrodes.

NGE has scarcely, if at all, been applied as an underlying substrate for PPy polymerisation and enzyme immobilisation despite its distinguishing advantages over a planar electrode. The closest example of an NGE application is the work of German et al. ${ }^{(11)}$ who fabricated a glucose oxidase (GOx) biosensor primarily by depositing gold nanoparticle sol on a carbon rod electrode. In this case, PPy was chemically synthesised over electrode-bound GOx. They revealed that AuNPs effectively allowed close communication between enzyme active sites and the electrode surface. Moreover, sizes of AuNPs notably affected electrochemical responses.

The morphology of the matrix for enzyme immobilisation is one of the critical factors for determining sensor performances because the matrix morphology directly affects substrate mass transfer from the bulk solution to enzyme active sites and electron transfer between enzyme active sites to the electrode surface. Various structures of synthesised PPy films have been reported. A fibre-like PPy film containing GOx entrapped multilamellar vesicles was reported by Olea et $a l .{ }^{(12)}$ In the absence of horseradish peroxidase (HRP), Elkaoutit et al. ${ }^{(13)}$ reported a highly ordered ellipsoidal shape of PPy on a highly oriented pyrolitic graphite electrode. In contrast, incorporation of HRP into the polymer film markedly affected Py electropolymerisation and finally the film morphology. Although these studies did not further demonstrate the use of the modified electrodes for electrochemical measurements, characterisation of the polymer films shed some light on their further applications.

The principal aim of this research was to investigate synergic effects of NGE and PPy on electrochemical responses. Effects of fabrication conditions, namely initial Py concentration and the number of scan cycles, on the PPy film morphology and current responses are highlighted in this article. A novelty of this sensor was the application of a NGE as an underlying substrate for a simple template-free electropolymerisation of PPy. Scanning electron microscopy (SEM) and atomic force microscopy (AFM) were applied for surface characterisation of the electrodes. Detection of phenol via catalysis of HRP was studied as a model reaction.

\section{Materials and Methods}

\subsection{Materials}

Horseradish peroxidase (131 U/mg HRP, EC 1.11.1.7) was purchased from Toyobo, and chloroauric acid trihydrate $\left(\mathrm{HAuCl}_{4} \cdot 3 \mathrm{H}_{2} \mathrm{O}\right)$ and pyrrole $(98 \%)$ were purchased from Sigma-Aldrich. Phenol was from Carlo Reagent, and hydrogen peroxide (30\%) was from Merck. All the chemicals used were of a laboratory grade. 


\subsection{Fabrication of nanogold electrodes}

The base glassy carbon electrode (GCE) was first successively polished with alumina slurries of 0.3 and $0.05 \mathrm{~mm}$, each for $5 \mathrm{~min}$. The electrode was rinsed with distilled water after each polishing step. Next, ultrasonication was alternately applied to the electrode in absolute ethanol and distilled water, each for $5 \mathrm{~min}$. Finally, the electrode was air-dried and ready for further modification. Electrodeposition of AuNPs was achieved using a single potential method by immersing the GCE in an aqueous solution of $\mathrm{HAuCl}_{4}(0.1,0.5$, and $1.0 \mathrm{mM})$ in the presence of $0.1 \mathrm{M} \mathrm{KNO}_{3}$. The voltage was applied at $-0.2 \mathrm{~V}$ (vs $\mathrm{Ag} / \mathrm{AgCl})$ for various deposition times $(5,30$, and $60 \mathrm{~s}$ ). The electrode obtained was designated as the NGE.

\subsection{Fabrication of NGE/HRP/PPy electrodes}

Electrochemical polymerisation of Py was carried out concomitantly with HRP immobilisation using a cyclic voltammetric method. The NGE was immersed in PBS (0.1 M, pH 7.4) containing a

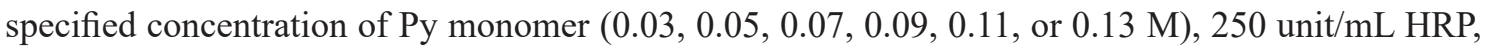
and $0.1 \mathrm{M} \mathrm{NaCl}$. The potential was cycled between 0.0 and $1.0 \mathrm{~V}$ (vs $\mathrm{Ag} / \mathrm{AgCl})$ at $10 \mathrm{mV} / \mathrm{s}$ for a specified cycle number $(5,10,15,20$, or 25 cycles). After rinsing with distilled water, the electrode (denoted as NGE/HRP/PPy) was stored in PBS $(0.1 \mathrm{M}, \mathrm{pH} 7.4)$ at $4{ }^{\circ} \mathrm{C}$ and used within the day of fabrication.

\subsection{Electrochemical measurements}

All electrochemical experiments were performed in a three-electrode cell (PGSTAT 30, Metrohm) using a GCE (or its modified form), a platinum wire, and $\mathrm{Ag} / \mathrm{AgCl}$ as working, auxiliary, and reference electrodes, respectively. Electrochemical characterisation of NGEs was achieved using a cyclic voltammetric method with a potential scan between -1.0 and $1.0 \mathrm{~V}$ at $0.1 \mathrm{~V} / \mathrm{s}$ in an aqueous solution of $10 \mathrm{mM} \mathrm{K}_{3}\left[\mathrm{Fe}(\mathrm{CN})_{6}\right]$ with $0.1 \mathrm{M} \mathrm{K}_{2} \mathrm{SO}_{4}$. Amperometric measurements of phenol were carried out at $-0.05 \mathrm{~V}$ in an unstirred $25{ }^{\circ} \mathrm{C}$ PBS $(0.1 \mathrm{M}, \mathrm{pH}$ 7.4) containing phenol and $\mathrm{H}_{2} \mathrm{O}_{2}$, both at concentrations of $50 \mu \mathrm{M}$.

\subsection{Characterisation of electrode surfaces}

SEM (JEOL JSM-6480LV) and AFM (Veeco, model nanoscope IV, mode: tapping Si-probe) were applied to surface characterisation of electrodes.

\section{Results and Discussion}

\subsection{Characterisation of the nanogold electrode}

Modification of the GCE with AuNPs was carried out to improve both the electronic and morphological properties of the planar electrode for greater current responses. Nucleation and growth of AuNPs on GCE were achieved according to the overall reduction reaction as follows: ${ }^{(14)}$

$$
\left[\mathrm{AuCl}_{4}\right]^{-}+3 \mathrm{e}^{-} \rightarrow \mathrm{Au}+4 \mathrm{Cl}^{-}
$$


SEM and AFM images revealed deposition of discrete nanoparticles on a relatively smooth planar GCE (Fig. 1). To select a suitable NGE, cyclic voltammetry was applied for $10 \mathrm{mM}$ $\mathrm{K}_{3}\left[\mathrm{Fe}(\mathrm{CN})_{6}\right]$ in an aqueous $0.1 \mathrm{M} \mathrm{K}_{2} \mathrm{SO}_{4}$ solution. Figure 2(a) shows effects of electrodeposition time on CVs of NGEs fabricated at a fixed $0.1 \mathrm{mM}\left[\mathrm{AuCl}_{4}\right]^{-}$. An approximately $46 \%$ increase in peak response was observed when the electrodeposition time was increased from 5 to $60 \mathrm{~s}$. With increasing $\left[\mathrm{AuCl}_{4}\right]^{-}$concentration to 0.5 and $1.0 \mathrm{mM}$, the deposition time showed virtually no effect

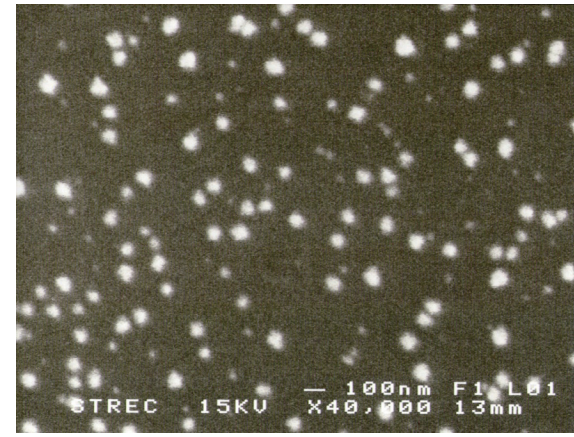

(a)

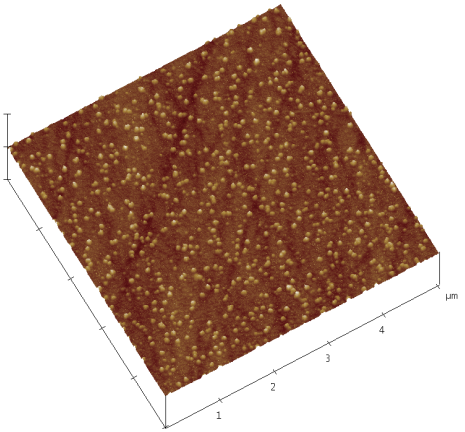

(b)

Fig. 1. (Color online) Images of (a) SEM and (b) AFM of a nanogold electrode fabricated using $0.5 \mathrm{mM}\left[\mathrm{AuCl}_{4}\right]^{]}$ in $0.1 \mathrm{M} \mathrm{KNO}_{3}$ aqueous solution at $-0.2 \mathrm{~V}$ ( $\left.\mathrm{vs} \mathrm{Ag} / \mathrm{AgCl}\right)$ for $30 \mathrm{~s}$.

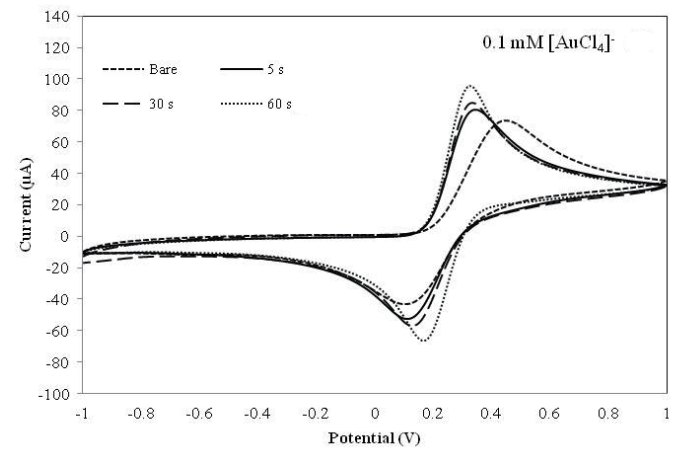

(a)

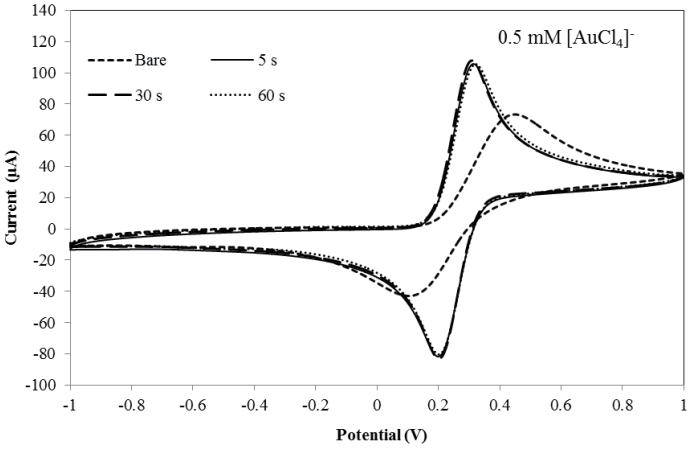

(b)

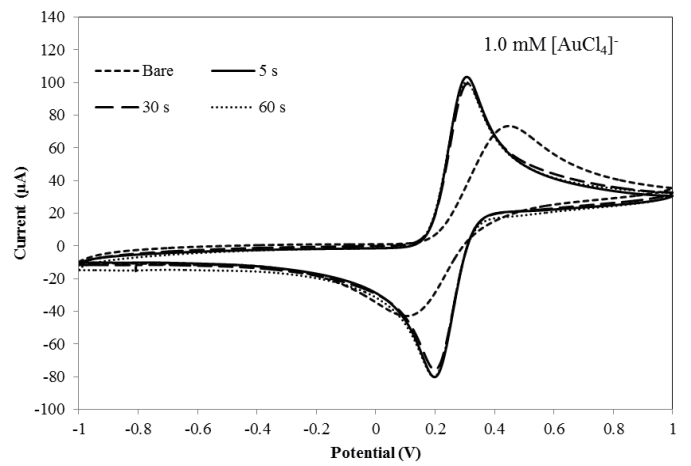

(c)

Fig. 2. Cyclic voltammograms of a bare GCE and NGEs fabricated with electrodeposition times of 5, 30, and $60 \mathrm{~s}$ at $-0.2 \mathrm{~V}\left(\mathrm{vs} \mathrm{Ag} / \mathrm{AgCl}\right.$ ) with $\left[\mathrm{AuCl}_{4}\right]^{-}$concentrations of (a) 0.1 , (b) 0.5 , and (c) $1.0 \mathrm{mM}$. The tested solution was $10 \mathrm{mM} \mathrm{K}_{4} \mathrm{Fe}(\mathrm{CN})_{6}$ in $0.1 \mathrm{M} \mathrm{K}_{2} \mathrm{SO}_{4}$. 
on electrochemical responses [Figs. 2(b) and 2(c)]. All the CVs reflected a typical reversible $\mathrm{Fe}^{3+}$ / $\mathrm{Fe}^{2+}$ redox process. The decreased peak-to-peak separation $\left(\Delta E_{\mathrm{p}}\right)$ from 0.37 to $0.12 \mathrm{~V}$ and the considerably enhanced peak current ( $\sim 1.7$-fold) of the NGE in comparison with the bare GCE were caused by the facilitated electron transfer and increased surface area of the modified electrodes. Conclusions were thus drawn that a NGE markedly outperforms a bare GCE. However, the variation in the morphology of these NGEs due to increasing electrodeposition time and $\left[\mathrm{AuCl}_{4}\right]^{-}$ concentration beyond the optimum conditions did not further enhance electrochemical responses.

The NGE realised using $0.5 \mathrm{mM}\left[\mathrm{AuCl}_{4}\right]^{-}$and $30 \mathrm{~s}$ electrodeposition time was selected and applied as an underlying layer for further modification with PPy and HRP. This electrode consisted of $4.05 \times 10^{9} \mathrm{AuNPs} / \mathrm{cm}^{2}$ with an average diameter of $56.2 \mathrm{~nm}$ and a roughness of $8.98 \mathrm{~nm}$ on a planar GCE. Based on the approximation that AuNPs were spherical, the surface area of the selected nanogold electrode was 1.4-fold higher than that of the planar electrode.

Modification of the NGE with HPR/PPy was achieved using an electropolymerisation method via a cascade of electron transfer and chemical reactions. The Py monomers were initially electrooxidised to free radical cations which then dimerised and formed neutral dimers. The dimers were, in the next cycle, electrooxidised and formed trimers. Repeated electron transfer and chemical reaction cycles finally resulted in the formation of PPy film on the NGE. Entrapment of HRP was achieved along with the polymerisation.

\subsection{Evaluation of modified electrodes for phenol detection}

To evaluate electrochemical responses of different modified electrodes, detection of phenol was used as a model process. Three consecutive enzymatic reactions were involved as follows: ${ }^{(15)}$

$$
\begin{gathered}
\operatorname{HRP}\left(\mathrm{Fe}^{3+}\right)+\mathrm{H}_{2} \mathrm{O}_{2} \rightarrow \operatorname{HRP}\left(\mathrm{Fe}^{5+}\right)+\mathrm{H}_{2} \mathrm{O}, \\
\operatorname{HRP}\left(\mathrm{Fe}^{5+}\right)+\text { Phenol } \rightarrow \operatorname{HRP}\left(\mathrm{Fe}^{4+}\right)+\text { Phenol }^{*}, \\
\operatorname{HRP}\left(\mathrm{Fe}^{4+}\right)+\text { Phenol } \rightarrow \operatorname{HRP}\left(\mathrm{Fe}^{3+}\right)+\text { Phenol }^{*}+\mathrm{H}_{2} \mathrm{O} .
\end{gathered}
$$

The sequence of reactions started with the oxidation of the HRP heme group by $\mathrm{H}_{2} \mathrm{O}_{2}$ (2) and the reduction of the heme group by phenol that acted as an electron mediator in reactions (3) and (4). Phenol $^{*}$, the oxidised product, was then reduced on the electrode surface. Therefore, the current response indirectly specified the phenol concentration in the solution.

Figure 3 shows amperometric results of related chemicals tested with different types of electrodes (GCE, NGE, GCE/PPy, NGE/PPy, GCE/HRP/PPy, and NGE/HRP/PPy). In cases where only $\mathrm{H}_{2} \mathrm{O}_{2}$ was present as the sole substrate, the electrocatalytic properties of HRP for the reduction of $\mathrm{H}_{2} \mathrm{O}_{2}$ and the direct electron transfer between HRP and electrode surfaces were observed as anticipated. ${ }^{(16-18)}$ However, marked increases (6.4- and 8.1-fold for GCE/HRP/PPy and NGE/HRP/PPy, respectively) in current responses were noted when phenol was added as an electron mediator. Thus, electrochemical interferences due to the direct electron transfer between active enzyme centres and electrode surfaces were considered insignificant. By comparing GCE/ $\mathrm{HRP} / \mathrm{PPy}$ with NGE/HRP/PPy for both $\mathrm{H}_{2} \mathrm{O}_{2}$ and $\mathrm{H}_{2} \mathrm{O}_{2}$ plus phenol systems, the results indicated a marked effect of AuNPs as an enhancer of current responses. The current responses increased 5.2- 


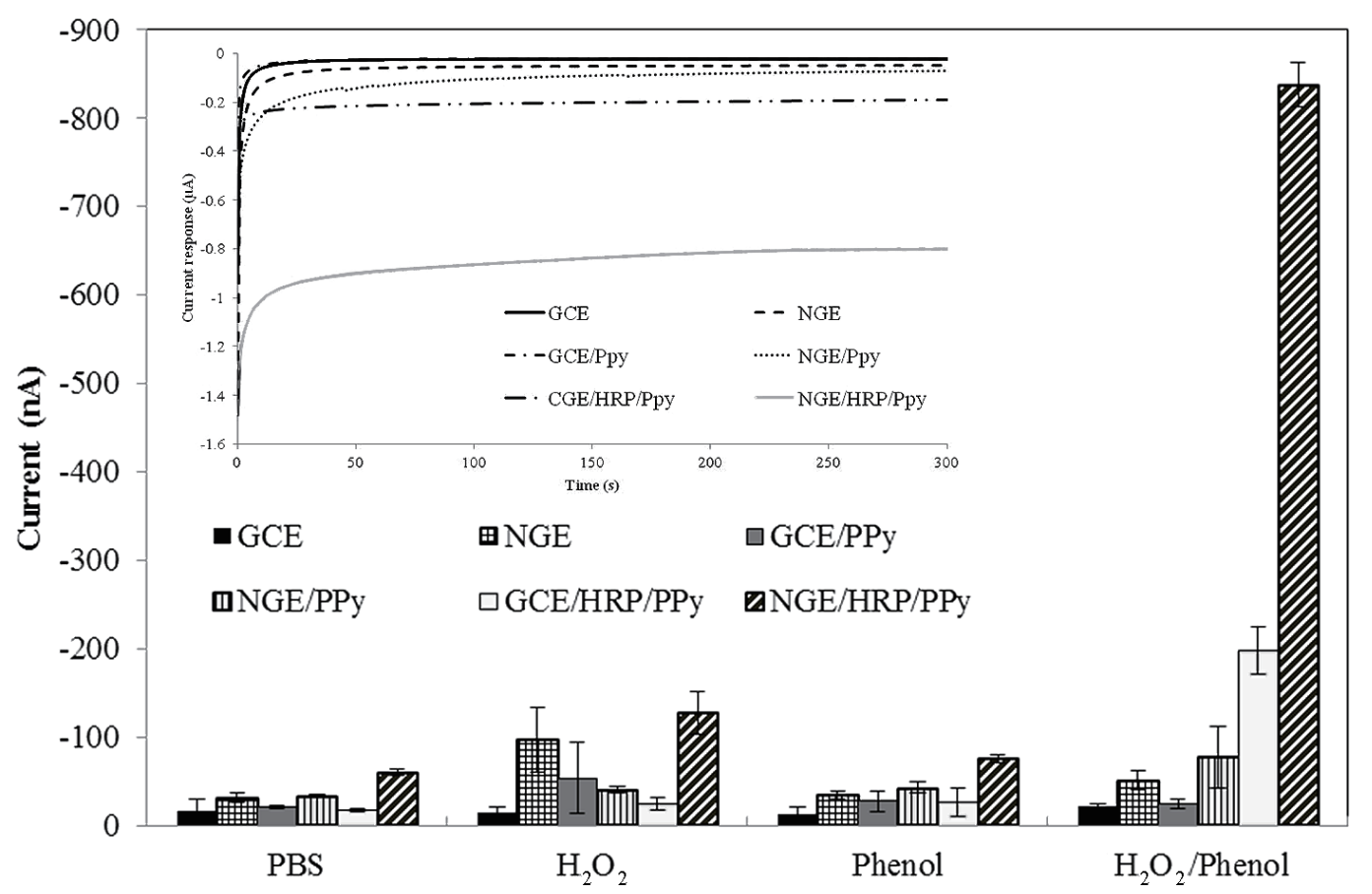

Fig. 3. Cathodic current responses at $-0.05 \mathrm{~V}$ (vs $\mathrm{Ag} / \mathrm{AgCl}$ ) for different working electrodes tested in various solutions: PBS (0.1 M, pH 7.4); $50 \mu \mathrm{M} \mathrm{H}_{2} \mathrm{O}_{2}$ in PBS; $50 \mu \mathrm{M}$ phenol in PBS; and 50/50 $\mu \mathrm{M} \mathrm{H}_{2} \mathrm{O}_{2} /$ phenol in PBS. Insert shows amperometric responses of different working electrodes in PBS containing $50 / 50 \mu \mathrm{M} \mathrm{H}_{2} \mathrm{O}_{2} /$ phenol.

and 4.5-fold for $\mathrm{H}_{2} \mathrm{O}_{2}$ and $\mathrm{H}_{2} \mathrm{O}_{2}$ plus phenol systems, respectively. We postulated synergy between AuNPs and PPy, which enhanced the catalytic property of HRP and the reduction of phenol ${ }^{*}$ on the electrode surfaces. Without PPy, the NGE demonstrated only a 1.7-fold increase in peak current in comparison with the bare GCE ( $§ 3.1)$. In summary, determination of phenol concentration using the NGE/HRP/PPy electrode was achieved with minimal direct electron transfer, and a marked synergic effect between AuNPs of NGE and PPy was discovered.

\subsection{Understanding the reaction system}

Since NGE/HRP/PPy proved to be highly effective for phenol detection, we applied this particular electrode to additional experiments. Immobilisation of HRP onto the NGE was concomitantly achieved with template-free electropolymerisation of the Py monomer using a cyclic voltammetry technique ( 0 and $1.0 \mathrm{~V}$ vs $\mathrm{Ag} / \mathrm{AgCl}$ at $10 \mathrm{mV} / \mathrm{s}$ ). Apart from the Py monomer and HRP, the solution for electropolymerisation also contained both weak acidic and non-acidic anions $\left(0.05 \mathrm{M} \mathrm{HPO}_{4}{ }^{2-}, 0.01 \mathrm{M} \mathrm{H}_{2} \mathrm{PO}_{4}^{-}\right.$, and $\left.0.1 \mathrm{M} \mathrm{Cl}^{-}\right)$. Owing to a relatively high isoelectric point of HRP (IEP 8.9), a positively charged enzyme was expected in the $\mathrm{pH} 7.4$ solution. This resulted in electrostatic repulsion between HRP and the oxidised PPy film during the oxidative scans. Nonetheless, a dopant of anions during the oxidation of the formed PPy could also diminish repulsive interactions. In contrast, reverse scans lessened these repulsive interactions whereby HRP entrapment could be enhanced. For this reason, the positively charged HRP was most likely 
immobilised by purely physical entrapment. This immobilisation mechanism was different from other reports on negatively charged enzymes where electrostatic attraction was considered an important mechanism. ${ }^{(13,19)}$ In addition, with negatively charged enzymes, the enzyme periphery could act as a new polymerization site for PPy, ${ }^{(13)}$ which was not likely the case in this study.

Figure 4 illustrates a schematic diagram of NGE/HRP/PPy with associated reactions. Since HRP was immobilised together with PPy polymerisation, a certain amount of HRP could directly be adsorbed on the surface of NGE, while the remaining would be entrapped in the PPy network some distances away from the electrode surface. Therefore, we postulated that electron transport via phenol as a mediator could be achieved either solely by phenol* diffusion or a combination of phenol ${ }^{*}$ diffusion and electron transport via $\pi-\pi$ conjugated PPy. The direct electron transfer between the oxidised HRP heme group and the electrode surface was found negligible as already discussed in $\S 3.2$.

\subsection{Effects of Py concentration}

The concentration of Py is one of the pivotal parameters governing the morphology of the electrodeposited PPy film and the electrochemical responses of the modified electrodes. The Py monomer acted as an initial substrate for electropolymerisation; therefore, a higher Py concentration certainly led to a faster PPy formation. During a fixed polymerisation time (15 scan cycles at 10 $\mathrm{mV} / \mathrm{s}$ ), a higher concentration of Py resulted in more developed PPy structures [Figs. 5(a)-5(f)]. The slow electropolymerisation due to low Py concentrations [0.03-0.07 M; Figs. 5(a)-5(c)] led to the formation of a PPy film with a nonuniform dispersion of nanobuds. However, at the highest Py concentration [0.13 M; Fig. 5(f)], electropolymerisation became too fast and resulted in obviously irregular structures of the nanorods. At moderate Py concentrations [0.09 and $0.11 \mathrm{M}$; Figs. 5(d) and 5(e)], the nanorods became homogeneous in size with rod diameters of approximately 0.09 and $0.13 \mathrm{~mm}$, respectively. As suggested by Debiemme-Chouvy, ${ }^{(20)}$ the template-free PPy nanorods

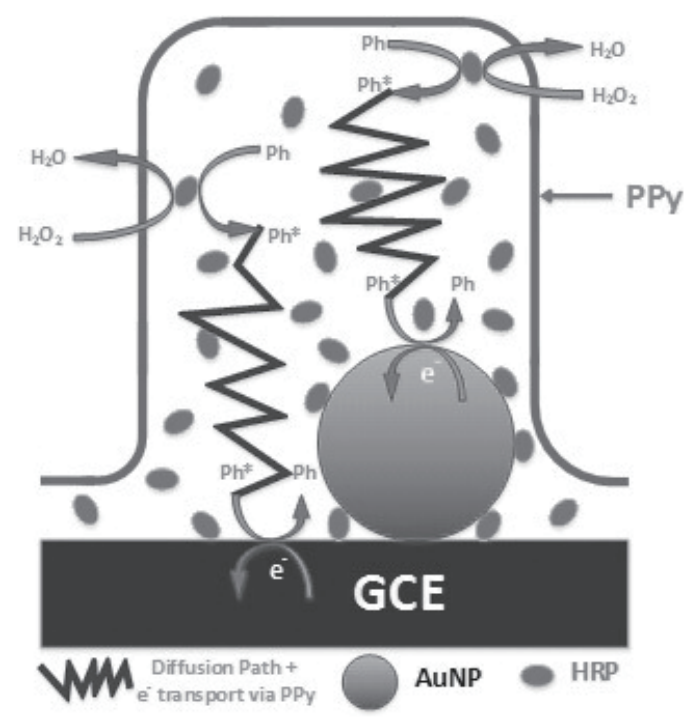

Fig. 4. Schematic diagram of NGE/HRP/PPy electrode with associated mass and electron transport processes. 


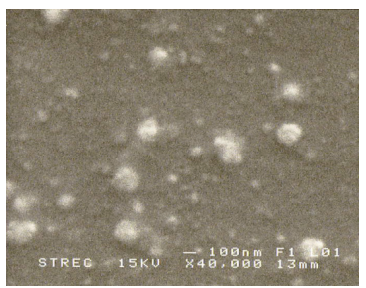

(a)

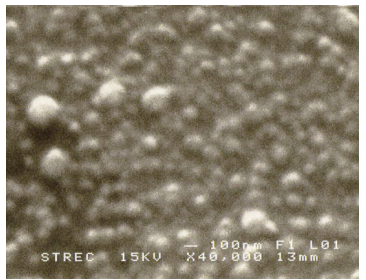

(c)

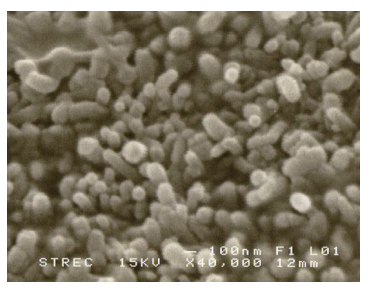

(e)

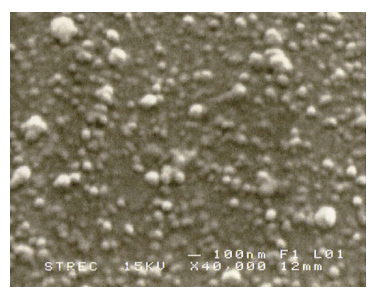

(b)

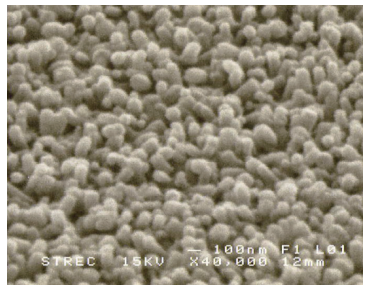

(d)

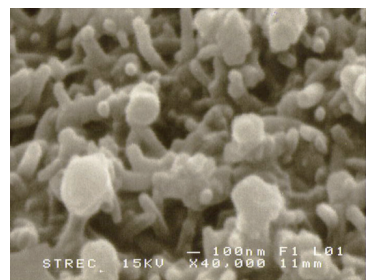

(f)

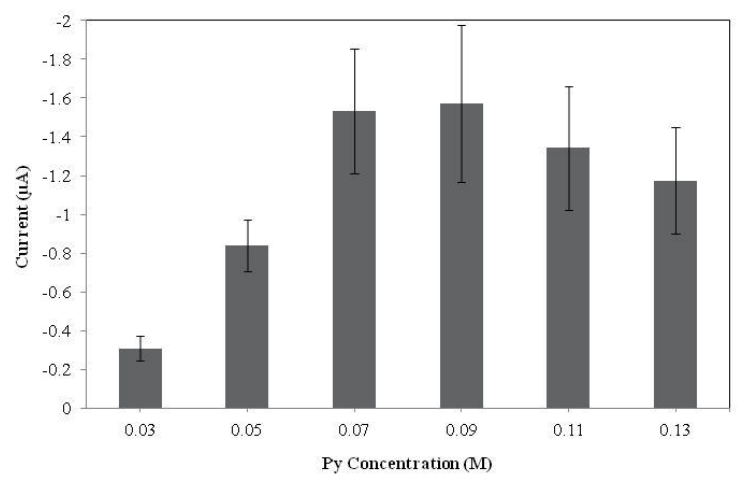

Fig. 5. SEM images (30 deg tilted) of NGE/ HRP/PPy surfaces fabricated at a fixed number of cycles of 15 (at $10 \mathrm{mV} / \mathrm{s}$ ) under various initial Py concentrations: (a) 0.03 , (b) 0.05, (c) 0.07, (d) 0.09, (e) 0.11 , and (f) $0.13 \mathrm{M}$.

Fig. 6. Cathodic current responses at $-0.05 \mathrm{~V}$ (vs $\mathrm{Ag} / \mathrm{AgCl}$ ) of NGE/HRP/PPy fabricated under various Py concentrations at a fixed number of cycles of 15 (at $10 \mathrm{mV} / \mathrm{s}$ ). The tested solution was $50 / 50 \mu \mathrm{M} \mathrm{H}_{2} \mathrm{O}_{2} /$ phenol in $0.1 \mathrm{M}$ PBS pH 7.4 at $25^{\circ} \mathrm{C}$.

obtained in this work were likely due to the presence of both weakly acidic and nonionic anions in the electropolymerisation solution. This is in contrast to Hermas et al. ${ }^{(21)}$ who reported the globular morphology of the PPy film obtained using a similar CV technique to the PPy polymerisation as applied in this work.

Figure 6 reveals marked effects of Py concentration on amperometric response for phenol detection. In the low concentration range $(0.03-0.07 \mathrm{M})$, electrochemical responses increased rapidly in an almost linear fashion, while they gradually decreased at concentrations higher than $0.09 \mathrm{M}$. The initial increase in electrochemical responses was most likely due to higher amounts of HRP entrapped and a higher solid/liquid interfacial area for mass transfer. However, after a certain limit, the higher enzyme loading and surface-area-to-volume ratio of the nanorods (at 0.11 and 0.13 M Py) were not found beneficial for electrochemical responses. This was most likely caused by the higher resistance of the thickened PPy film and/or changes in the characteristics of the PPy network at high Py concentrations. Electrochemical responses, therefore, were lower, despite higher HRP loadings. This recommendation was in line with $\mathrm{Lu}$ et al. ${ }^{(22)}$ who revealed that the conductivity of polyaniline (PANI) nanostructures decreased with increasing 1D diameter. Similarly to 1D PANI nanostructures, PPy nanorods likely exhibited a size effect on conductivity. 


\subsection{Effects of number of scan cycles}

Effects of the number of scan cycles for electropolymerisation were tested at a fixed Py concentration of $0.09 \mathrm{M}$ at $10 \mathrm{mV} / \mathrm{s}$. A higher scan number reflected a longer reaction time. Figures 7(a)-7(e) illustrate the development of a PPy film with a reaction time that shows that the surface coverage of the NGE was primarily achieved before the formation of nanobuds [Fig. 5(a)] and finally for nanorods of different lengths [Figs. 5(b)-5(e)]. The nanorods were, at the least, doubled in length when the number of cycles increased from 10 to 25 while approximately the same diameter (average of $97 \mathrm{~nm}$ ) was maintained.

Amperometric responses for phenol detection of various scan cycles are shown in Fig. 8. Higher scan numbers resulted in PPy films with higher surface-area-to-volume ratio and enzyme loading, yet a longer distance for phenol* diffusion and electron transport to the electrode surface. The initial increase in current response with the number of scan cycles was undoubtedly due to the increase in HRP loading. Surprisingly, current responses dropped markedly after 10 scan cycles, and a $62.8 \%$ current reduction was observed when the number of cycles was increased from 10 to 25. We postulated that denaturation of the immobilised HRP after prolonged electropolymerisation could be the main cause.

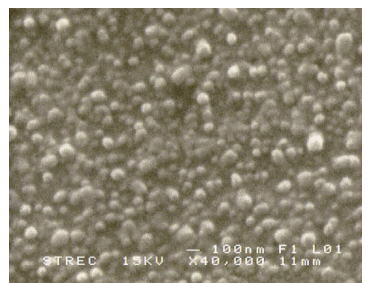

(a)

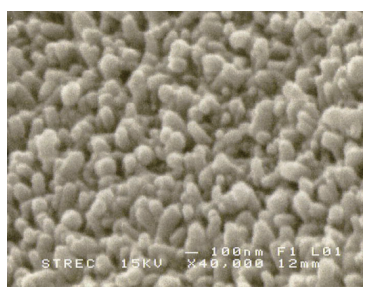

(b)

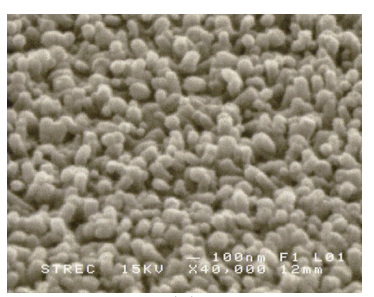

(c)

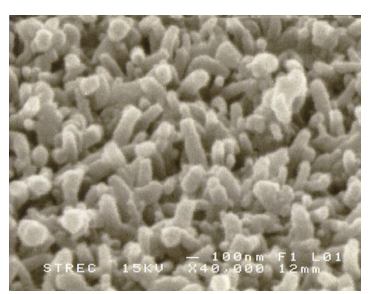

(d)

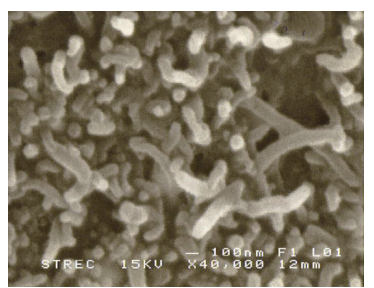

(e)

Fig. 7. SEM images (30 deg tilted) of NGE/HRP/ PPy surfaces fabricated at a fixed Py concentration of $0.09 \mathrm{M}$ under various numbers of scan cycles: (a) 5, (b) 10 , (c) 15 , (d) 20 , and (e) 25 at $10 \mathrm{mV} / \mathrm{s}$.

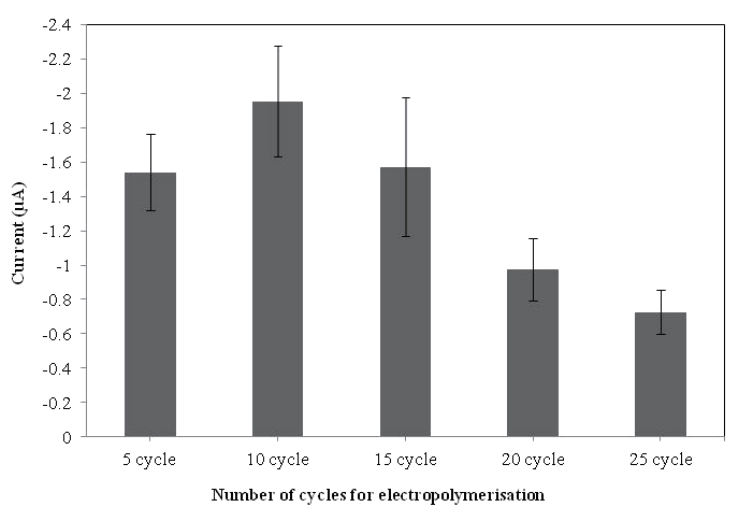

Fig. 8. Cathodic current responses at $-0.05 \mathrm{~V}$ (vs $\mathrm{Ag} / \mathrm{AgCl}$ ) of NGE/HRP/PPy fabricated under various numbers of scan cycles (at $10 \mathrm{mV} / \mathrm{s}$ ) at a fixed Py concentration of $0.09 \mathrm{M}$. The tested solution was $50 / 50 \mu \mathrm{M} \mathrm{H}_{2} \mathrm{O}_{2} /$ phenol in $0.1 \mathrm{M}$ PBS pH 7.4 at $25^{\circ} \mathrm{C}$. 


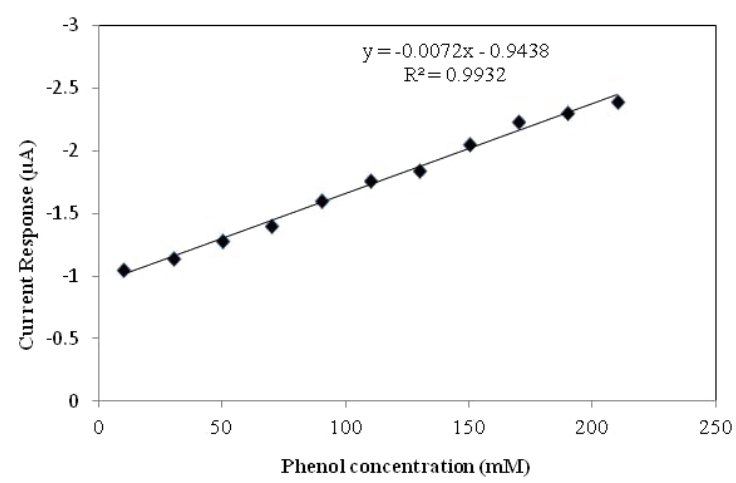

Fig. 9. Calibration curve of phenol determination using the optimum NGE/HRP/PPy electrode. Applied potential: $-0.05 \mathrm{~V}$ (vs $\mathrm{Ag} / \mathrm{AgCl}$ ), $50 \mu \mathrm{M} \mathrm{H}_{2} \mathrm{O}_{2}$ in $0.1 \mathrm{M}$ PBS pH $7.4,25^{\circ} \mathrm{C}$.

Figure 9 shows a calibration curve of the NGE/HRP/PPy electrode (fabricated with $0.09 \mathrm{M}$ Py and 10 scan cycles) for phenol detection. The linear range, sensitivity, and detection limit $(S / N=3)$ were determined at $0.01-0.2 \mathrm{mM}, 7.2 \mu \mathrm{M} / \mathrm{mM}$, and $15.0 \mu \mathrm{M}$, respectively.

\section{Conclusions}

In this article, a novel application of a NGE as an underlying substrate for concomitant polymerisation of Py and immobilisation of HRP is described. A bare NGE was found to electrochemically outperform a GCE with an increase of 1.7 -fold in current response to a $\mathrm{Fe}^{3+} /$ $\mathrm{Fe}^{2+}$ redox couple. This was most likely due to an increase of approximately $40 \%$ in the surface area of the electrode. Moreover, application of the NGE as a platform for HRP-catalysed (NGE/ HRP/PPy) phenol detection resulted in an astonishingly 4.5-fold higher current than that for GCE/ HRP/PPy. The synergy between AuNPs (of NGE) and PPy was suggested. The reaction process was found to be a negligible direct electron transfer. Interestingly, this work also demonstrates the template-free synthesis of PPy nanorods on NGEs and their applications to phenol detection. The initial Py concentration and the number of scan cycles exhibited marked effects on the polymer film morphology and electrochemical responses. Higher Py concentration and number of scan cycles similarly resulted in lengthened PPy nanorods with undoubtedly higher HRP loadings. Amperometric reponses were, therefore, increased to the optimum points with these two parameters. Further increases in Py concentration and the numbers of cycles resulted in lower currents. We postulated this to be caused by the change in PPy conductivity due to the size effect and denaturation of HRP after prolonged electropolymerisation. An NGE could certainly be applied as an underlying substrate for other enzyme/polymer or sole polymer matrices for the detection of other analytes in biosensors and chemical sensors. 


\section{Acknowledgements}

This research has been supported by the Ratchadaphiseksomphot Endowment Fund of Chulalongkorn University RES 560530186-FW and Chemical Engineering Research Unit for Value Adding of Bioresources. The authors would also like to acknowledge Miss Angkana Phongphut and Mr. Zunpitch Kwanyuen for the artwork.

\section{References}

B. Haghighi and M. A. Tabrizi: Colloid. Surface B 103 (2013) 566.

2 E. M. I. Ekanayake, D. M. G. Preethichandra, and K. Kaneto: Sens. Actuators, A 132 (2008) 166.

3 J. Riu, A. Maroto, and F. X. Rius: Talanta. 69 (2006) 288.

4 S. J. Guo and E. K. Wang: Anal. Chim. Acta. 598 (2007) 181.

5 J. Li and X. Lin: Sens. Actuators, B 124 (2007) 486.

6 J. Gong, L. Wang, and L. Zhang: Biosen. Bioelectron. 24 (2009) 2285.

7 H. Huang, P. Ran, and Z. Liu: Bioelectrochemistry 70 (2007) 257.

8 G.-Y. Kim, J. Shim, M.-S. Kang, and S.-H. Moon: J. Hazard. Mater. 156 (2008) 141.

9 S.-F. Liu, X.-H. Li, Y.C. Li, Y.F. Li, J.-R. Li, and L. Jiang: Electrochim. Acta. 51 (2005) 427.

10 A. K. Das and C. R. Raj: J. Electroanal. Chem. 638 (2010) 189.

11 N. German, A. Ramanavicius, J. Voronovic, and A. Ramanaviciene: Colloid. Surface. A. 413 (2012) 224.

12 D. Olea, P. Moreau, and C. Faure: J. of Electroanal. Chem. 605 (2007) 125.

13 M. Elkaoutit, A. H. Naggar, I. Naranjo-Rodriguez, M. Dominguez, and J. L. H. de Cisneros: Synthetic Met. 159 (2009) 541.

14 L. Komsiyska and G. Staikov: Electrochim. Acta. 54 (2008) 168.

15 S. S. Rosatto, L. T. Kubota, and G. D. O. Neto: Anal. Chim. Acta. 390 (1999) 65.

16 J. Xu, R. Peng, Q. Ran, Y. Xian, Y. Tian, and L. Jin: Talanta. 82 (2010) 1511.

17 Y. Zhang, R. Yuan, Y. Chai, Y. Xiang, C. Hong, and X. Ran: Biochem. Eng. J. 51 (2010) 102.

18 L. Fernandez, I. Ledezma, C. Borras, L. A. Martinez, and H. Carrero: Sens. Actuators, B 182 (2013) 625.

19 M. Singh, P. K. Kathuroju, and N. Jampana: Sens. Actuators, B 143 (2009) 430.

20 C. Debiemme-Chouvy: Electrochem. Commun. 11 (2009) 298.

21 A. A. Hermas, S. S. Al-Juaid, S. A. Al-Thabaiti, A. H. Qusti, and M. A. Salam: Prog. Org. Coat. 75 (2012) 404.

22 X. Lu, W. Zhang, C. Wang, T.-C. Wen, and Y. Wei: Prog. Polym. Sci. 36 (2011) 671. 